\title{
ON THE ELECTRICAL RESISTANCE OF LASER JOINED METAL SHEETS
}

\author{
Andor Körmöczi' ${ }^{1}$, Gábor Horváth ${ }^{1}$, Tamás Szörényi ${ }^{1}, Z^{2}$ solt Geretovszky ${ }^{1}$ \\ ${ }^{1}$ University of Szeged, Department of Optics and Quantum Electronics, \\ H-6720 Szeged, Dóm tér 9., Hungary
}

DOI: https://doi.org/10.14232/kvantumelektronika.9.23

\section{Introduction}

Nowadays, environmentally friendly solutions are gaining more and more grounding. Thanks to this trend hybrid or fully electric propulsion systems emerge as alternatives to conventional internal combustion engines [1]. The limited capacity of the available battery cells storing the electrical energy and the high energy loss due to the large number of joints necessary to integrate the individual cells into battery packs lead to considerable losses and otherwise unnecessary solutions to implement (e.g. thermal management subsystems) [2,3].

The extent of the energy loss is determined by the electrical resistance of the joints. Laser welding and laser assisted filler-based joining (soldering and brazing) are promising alternatives to traditional techniques in producing high quality bonds while meeting even the strictest requirements of the aviation industry [4,5]. With laser soldered joints possessing excellent electrical properties can be created at low thermal loads. This is one of the reasons why laser soldering is a preferred technique in electronics in general and during assembling battery pack, in particular.

In this paper the challenges of electrical characterization of joints created by laser-assisted techniques are discussed.

\section{Materials and methods}

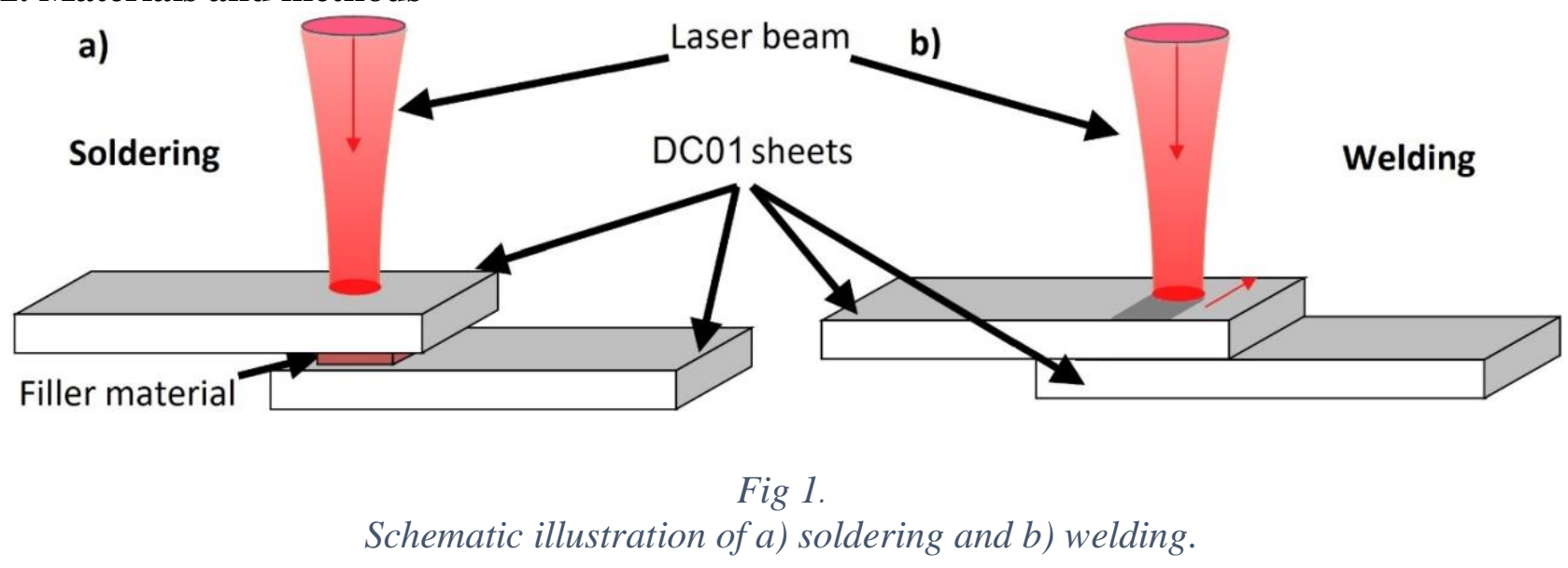

Joints were formed between two $0.5 \mathrm{~mm}$ thick, $15 \mathrm{~mm}$ wide and $30 \mathrm{~mm}$ long DC01 steel sheets used to replace Hilumin ${ }^{\circledR}$, which is the material of the caps of Li-ion cylindrical cells. Hilumin ${ }^{\circledR}$ is DC04 steel sheet coated with a nickel layer of several micrometer thickness. The similarity of DC04 and DC01 in chemical composition, electrical and mechanical properties justified the usage of the latter for our present study. The two sheets were connected in a lap geometry to model the "battery cap to bus bar" joint configuration, which is the most widely used geometry in battery pack assembly. The steel plates were clamped together in a home-made jig. In case of soldering, the filler was applied 
between the two steel pieces in form of sheets of $0.16 \pm 0.01 \mathrm{~mm}$ thickness and $5.0 \pm 0.1 \mathrm{~mm}$ width as shown in Figure 1a. The length of the filler sheet was varied between 2.0 and $6.0 \mathrm{~mm}$. The tin-based filler (Sn99.3Cu0.7) used had a liquidus temperature of $227^{\circ} \mathrm{C}$ and contained a rosin-based flux for insuring the wetting, as well [6].

In case of welding, the jig was moved under the laser beam with a high-speed, programmable motorised table (Allen Bradley Ultra 3000) at $50 \mathrm{~mm} / \mathrm{s}$ translational speed. The schematic is shown in Figure $1 b$.

As a heat source a cw Yb-doped fiber laser (SPI SP-400C-0005), emitting $400 \mathrm{~W}$ maximum power at $1071 \mathrm{~nm}$ with a $\mathrm{M}^{2}$ value around 1.08 was used. The sample was irradiated by the laser beam at nearly perpendicular angle of incidence $\left(\sim 10^{\circ}\right)$. In case of welding, a glass lens of $300 \mathrm{~mm}$ focal length produced a spot size of about $0.3 \mathrm{~mm}$ in diameter on the sample surface. In case of soldering, a glass lens of $1000 \mathrm{~mm}$ focal length was used to illuminate an $\sim 4.5 \mathrm{~mm} 1 / \mathrm{e}^{2}$ diameter spot on the upper surface of the sheet pair. In situ power measurement was also realized with a photodiode (Thorlabs S130C).

The measurement of the electrical properties of the laser-formed joints is an interesting and challenging task with no standardized methods available. The main problem is that it is impossible to measure directly the resistance of the joint, because no matter how close we get with needle tipped probes, the measured resistance will always include the resistance of the base sheets to be bonded. The joints have a resistance, scattering between 10 to $100 \mu \Omega$. These values are in the order of the resistance of the measurement probes. To eliminate this problem, a four-point probe measurement geometry [7] was used: the current at the ends of the plates was feeding by a TTI CPX200 external power supply, and the voltage drop was measured by a Keithley 2401 multimeter on a $21 \mathrm{~mm}$ long section so that the geometric centre of the joint coincided with the middle point of the voltage measurement distance [8]. This method is perfectly suitable for comparing the electrical characteristics of different samples. However, it does not give exact values for the joint resistance.

\section{Results}

\subsection{The assessment of the methods developed for measuring the electrical resistance of joints}

In order to accurately determine low resistances, the most trivial solution is to pass high current through the resistance to produce a voltage drop that can be measured with sufficient accuracy. As an example, to determine a $15 \mu \Omega$ resistance with $1 \%$ measurement error a current of 180 A is required, at least [7]. The use of such high currents may cause a temperature rise within the samples that changes the resistance, ultimately it even may cause damage in the structure of the joint. Therefore, instead of using high currents other solutions should be found.

One of the solutions for overcoming the above problem, coined as asymptotic method, is to measure the resistance at several, gradually increasing current values and then plot the resistances as a function of the current to determine the value to which the curve is approaching. As an example, the resistance of a sample, welded with a laser power of $400 \mathrm{~W}$ and a scanning speed of $50 \mathrm{~mm} / \mathrm{s}$, as a function of the measuring currents is shown in Figure 2a. Another approach, the slope method is more accurate. Here by plotting the voltage-current pairs measured at several currents, the slope of the straight line fitted to the measurement points will provide the value of the resistance under study. An additional advantage of the slope method is that it is self-checking. If all points fit well to the line, it means that during the measurement the current flow did not cause any temperature rise in the system, i.e. the resistance was constant. The results obtained by the slope for the same welded sample is shown in Figure $2 b$. 

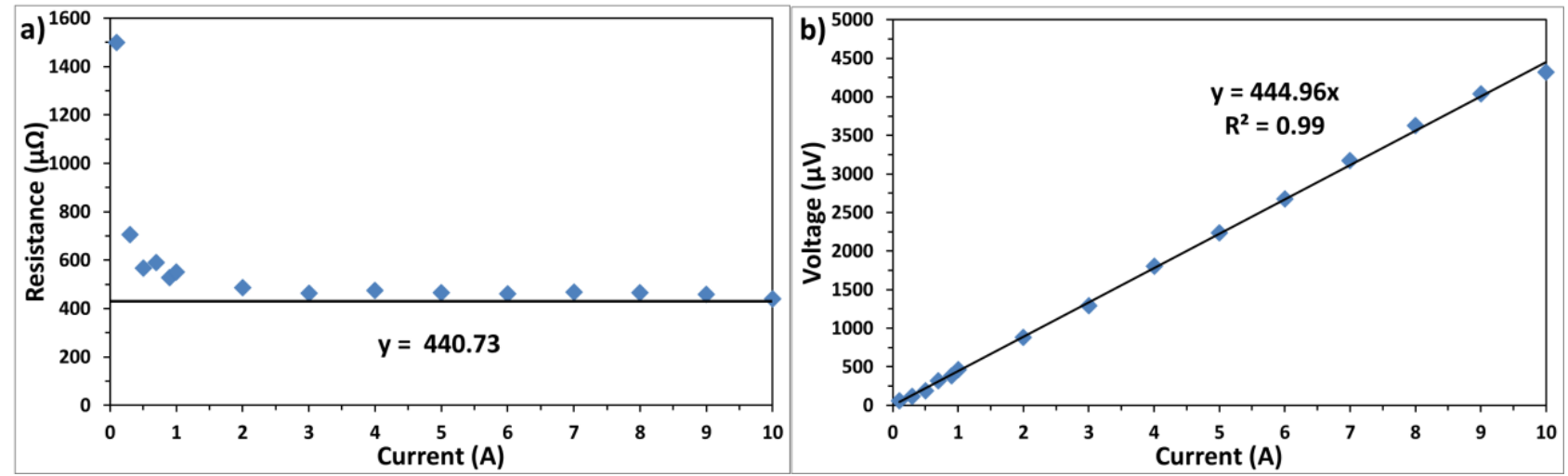

Fig 2.

Evaluation of the measurement of the resistance of a sample welded with laser power of $400 \mathrm{~W}$ and scanning speed of $50 \mathrm{~mm} / \mathrm{s}$ by the a) asymptotic and the b) slope method.

The slope method was used throughout the measurements reported below. $10 \mathrm{~A}$ was determined as the maximum current value allowing measurement without any noticeable temperature rise. Since the analysis of the results of the preliminary measurements revealed that to produce a measurement error below $1 \%$ in the resistance at least 6 measurement points were necessary, 0.1, 0.5, 1, 3, 6 and $10 \mathrm{~A}$ were selected as measurement points to cover the entire current range.

The resistance values calculated from these measurements do not provide the joint resistance directly, but reflect the net resistance of the metal sheets and the joint in between the two inner measurement probes (of the 4-point probe method). Therefore, for examining the contribution of the resistance of the joint to that measured on the sample, the change in resistance was monitored as a function of the distance between the two voltage probes. When analysing the results two cases were distinguished: measurements in the far and near zones. To the far zone (indicated by the blue lines in Figure 3) belonged those cases where the measuring probes were outside of the joining area, while in the near zone (marked in red) the measurement took place inside the joining area as illustrated in Figure 3.

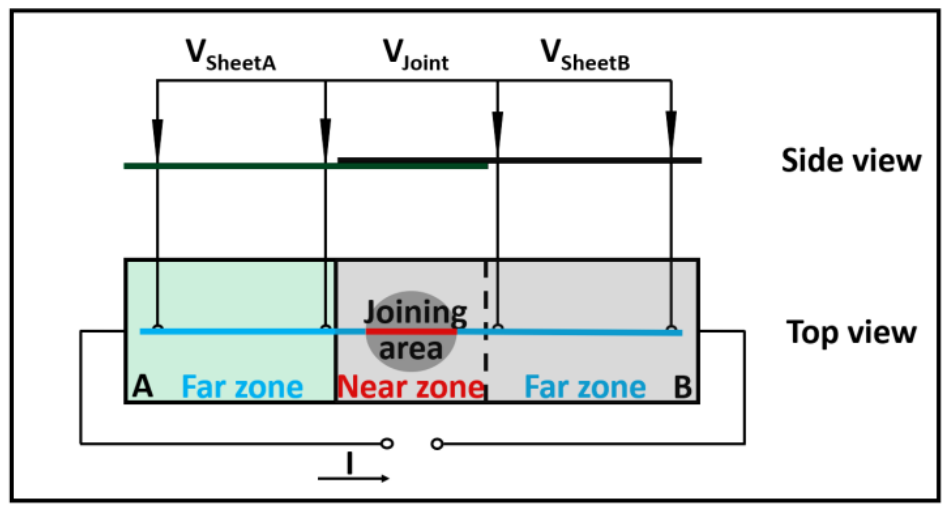

Fig 3.

The difference between the far (blue) and near (red) zone during the four-point probe measurement of the electrical resistance in case of soldering.

In case of soldering, the joining area was close to circular in shape with a diameter up to $10 \mathrm{~mm}$. In welding, the joining area was much smaller: the width of the welding seam, i.e. the relevant dimension of the seam in relation to the resistance measuring, was around $0.5 \mathrm{~mm}$. Accordingly, when performing the resistance measurements at 3, 6, 9, 12, 15, 21, 41 and $81 \mathrm{~mm}$ distances both zones could be tested for the soldered samples, while all measurement points laid in the far zone in case of welding. 


\subsection{The far zone}

Soldering were performed at $120 \mathrm{~W}$ laser power for $5 \mathrm{~s}$ irradiation time, while for welding $360 \mathrm{~W}$ laser power and $50 \mathrm{~mm} / \mathrm{s}$ scanning speed was used. For comparison, the resistance of a steel sheet, used for our joining experiments, was also measured, and will be reported as reference (base metal). In Figure 4 the resistance values measured on the three sample types are plotted as a function of the measuring distance. The boundary between the two zones can be defined only in case of soldering where the measured points fit on lines of different slopes in the two zones. In the case of welding, no such limit was observed, in line with the expectation outlined above.
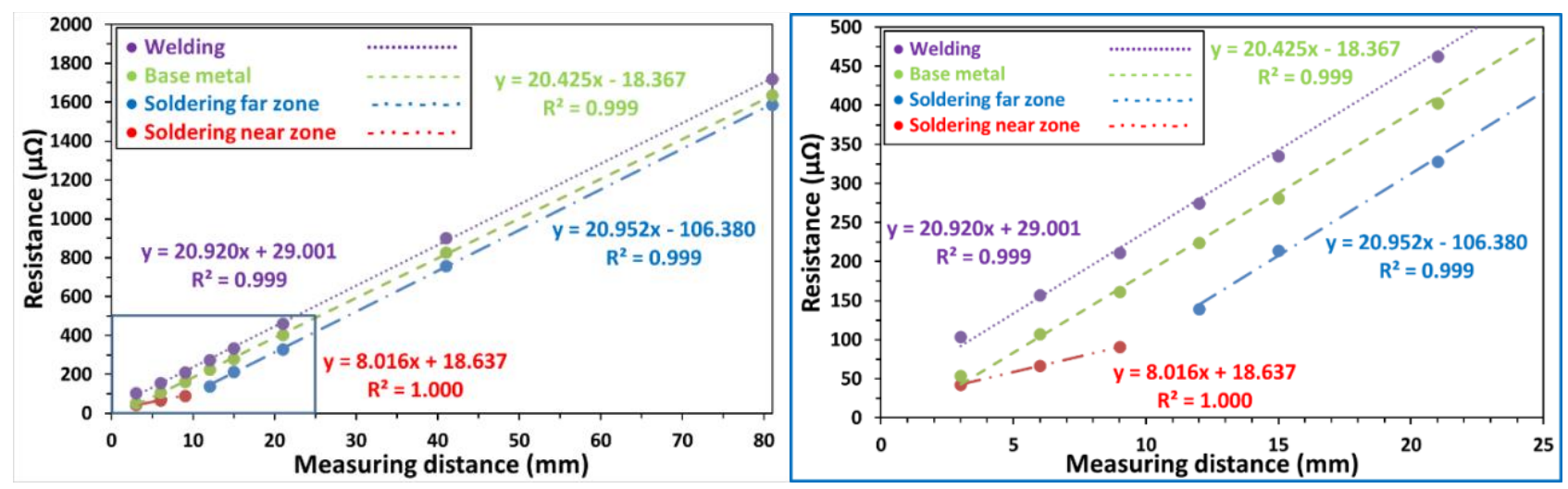

Fig 4.

Resistance values measured on welded and soldered samples and a DC01 plate without bonding as a function of the measuring distance.

In the far zone the slopes of the three lines agreed within $2 \%$. Based on this finding and considering the well known

$$
R=\rho \cdot \frac{l}{A}
$$

correlation, the slope of the resistance $v s$. distance curves in the far zone are interpreted as a material property, i.e. a material specific resistivity-like quantity, normalized to the joining area. The fact that in this zone the resistance of the steel sheets is dominant was further proved by measuring the resistance of different materials.

\begin{tabular}{|c|c|c|}
\hline Material of the sheet & Thickness $(\mathrm{mm})$ & Slope $(\mu \Omega / \mathrm{mm})$ \\
\hline DC01 & 0.50 & 20.425 \\
\hline Stainless steel & 0.50 & 22.543 \\
\hline Acid resistant steel & 0.50 & 58.075 \\
\hline Hilumin ${ }^{\circledR}$ & 0.25 & 322.310 \\
\hline Aluminium alloy & 1.00 & 1.799 \\
\hline Aluminium (99\%) & 1.00 & 1.717 \\
\hline Copper alloy (bronze) & 1.00 & 4.144 \\
\hline
\end{tabular}

Table 1.

The slope of the resistance vs. distance curves in the far zone for 7 different materials. 
As shown in Table 1 for the materials of high electrical conductivity (such as aluminium or copper alloy) the measured slopes proved to be smaller, while for the less conductive materials (such as the steel sheets and Hilumin $\left.{ }^{\circledR}\right)$ higher slopes were measured, supporting the above presented interpretation.

It can be observed in Figure 4 that in case of welding (purple dotted line) all measured resistances were higher than the respective resistances of the base material sheet (green dashed line), while laser soldered samples (blue dot-dashed line) exhibit lower resistance that the base metal reference . This difference may be interpreted so that a new component, i.e. the solder with inherently lower resistance is added to the equivalent circle during soldering, while the resistance of the weld seam is higher than that of the base metal due to the finer grain structure of the resolidified material.

\subsection{The near zone in case of soldering}

Resistance values in the near zone could only be measured in case of soldered samples, because the lateral extent of the weld seam was not large enough. To confirm the interpretation of the slopes of the resistance-distance curves put forward above, the measurements were repeated on samples containing fillers of 2.0, 4.0 and $6.0 \mathrm{~mm}$ length, ending up with 1.6, 3.2 and $4.8 \mathrm{~mm}^{3}$, while keeping all other process parameters constant. Since the amount of the solder determines the size of the bonding area, an increase in the solder volume means an increase in the joint area. In the far zone, the slopes of the lines moving continuously away from the line of the unbonded steel sheet (green line) were again constant within $2 \%$ as visualized in Figure 5. The measured resistance decreased monotonically with increasing amount of the solder.

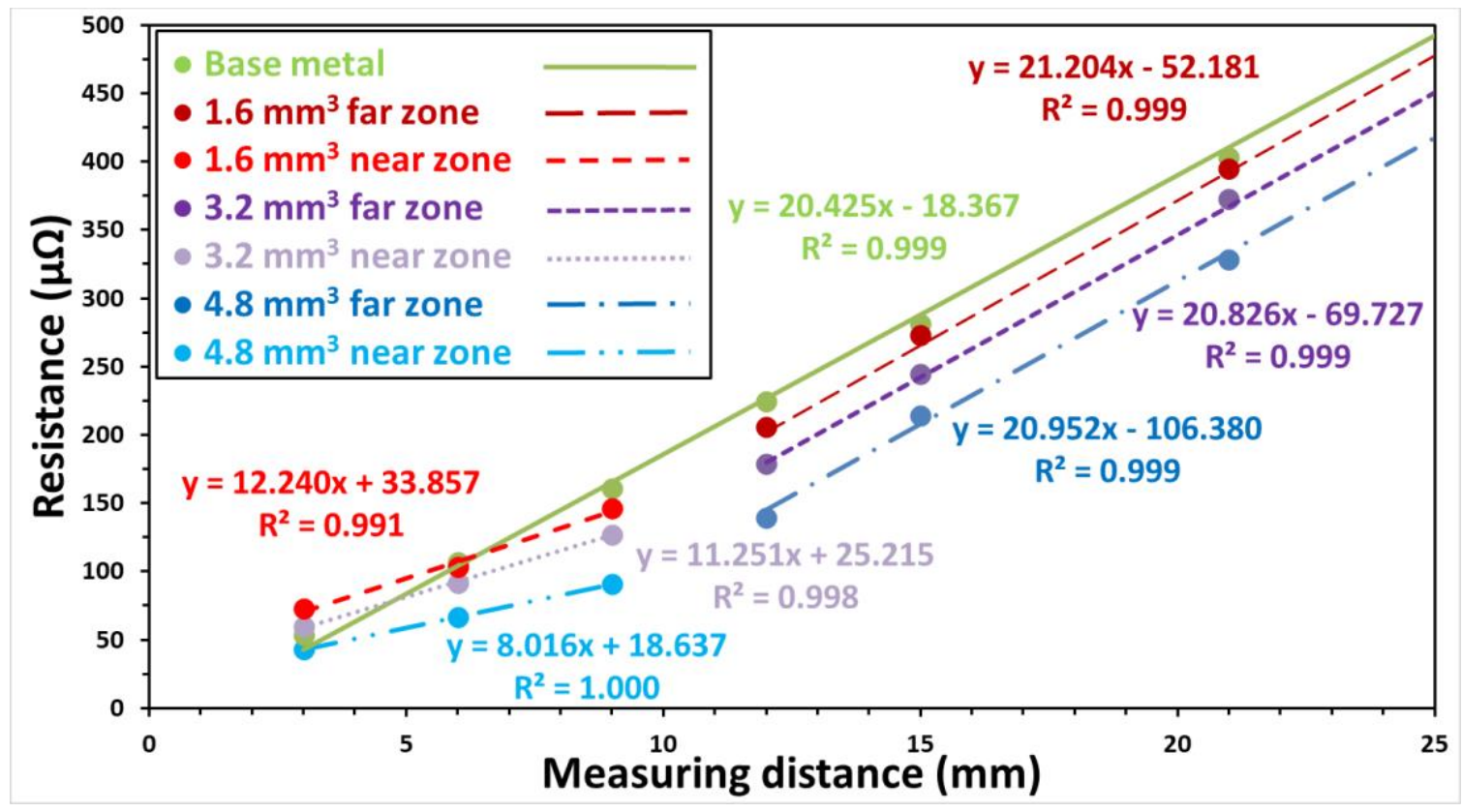

Fig 5 .

The resistance as a function of measuring distance for soldered samples with different amounts of solders.

In the near zone the slope of the fitted lines decreased with increasing amount of solder, indicating that the resistance of filler material became more and more significant in determining the resistance of the system. The decrease in the slopes is due to the fact, that the solder is a better conductor than the base steel sheet. The resistance values decreasing with decreasing measurement distance approach the actual joint resistance. 


\section{Conclusion}

One key issue when using electric drive chains is energy efficiency. When the energy is provided by a battery pack the energy loss is determined by the electrical resistance of the connections between individual cells. The measurement of the electrical characteristics of the joints is not yet standardized. In this paper the benefits and problems of a four-point resistance measurement method, developed for measuring the electrical resistance of joints, were presented. The resistance values were determined by plotting voltage-current pairs according to the slope method, eliminating the problem of heating caused by high currents. It was shown that the resistance of two lap welded sheets is higher, while that of the soldered joint is smaller than the resistance of the base metal sheet.

Future goals include modelling near and far zone behaviours, and comparing them with the experimental results, as well as further characterisation of joints made by welding and soldering Hilumin ${ }^{\circledR}$ sheets.

\section{Acknowledgements}

The work is supported by the EFOP-3.6.1-16-2016-00014 project, entitled "Research and development of disruptive technologies in the area of e-mobility and their integration into the engineering education".

We would like to acknowledge Edutus University for providing the laser source and other supplementary equipment for our experiments.

\section{References}

[1] I. Gál, I. Jankovics, Gy. Bicsák, Á. Veress, J. Rohács, D. Rohács: Conceptual design of a small 4-seater aircraft with hybrid propulsion system, Innováció és Fenntartható Felszíni Közlekedés konferencia 2017, pp. 143-150. (2017)

[2] V. Madonna, P. Giangrande, M. Galea: Electrical power generation in aircraft: review, challenges, and opportunities. IEEE transactions on transportation electrification, Vol. 4, No. 3, pp. 646-659, (2018)

https://doi.org/10.1109/TTE.2018.2834142

[3] S. S. Lee, T. H. Kim, S. J. Hu, W. W. Cai, J. A. Abell: Joining technologies for automotive lithiumion battery manufacturing: a review, ASME 2010 International Manufacturing Science and Engineering Conference, Vol. 1, pp. 541-549 (2010)

https://doi.org/10.1115/MSEC2010-34168

[4] M. J. Brand, P. A. Schmidt, M. F. Zaeh, A. Jossen: Welding techniques for battery cells and resulting electrical contact resistances, Journal of Energy Storage Vol. 1, pp. 7-14, (2015) https://doi.org/10.1016/j.est.2015.04.001

[5] M. J. Brand, E. I. Kolp, P. Berg, T. Bach, P. Schmidt, A. Jossen: Electrical resistances of soldered battery cell connections, Journal of Energy Storage Vol. 12, pp. 45-54, (2017)

https://doi.org/10.1016/j.est.2017.03.019

[6] Datasheet of lead free solder, FELDER GMBH Löttechnik, accessed November 2020, https://www.felder.de/files/felder/pdf/EN_18-ISO-Core_RA_lead-free.pdf 
[7] P. A. Schmidt, M. Schweier, M. F. Zaeh: Joining of lithium-ion batteries using laser beam welding: electrical losses of welded aluminum and copper joints, 31st International Congress on Applications of Lasers and Electro-Optics., pp. 915-923., (2012)

https://doi.org/10.2351/1.5062563

[8] A. Körmöczi, G. Horváth, T. Szörényi, and Zs. Geretovszky: Laser assisted filler-based joining for battery assembly in aviation, SAE Int. J. Aerosp., Vol. 13, No. 2 (2020)

https://doi.org/10.4271/01-13-02-0011 